\title{
Influence of Different Structural Parameters of Rotary Flow Jetting Tool on Gas-Liquid Flow State
}

\author{
Leilei Liu, Jie Liu* \\ School of Petroleum Engineering, Yangtze University, Wuhan 430100, China
}

Corresponding Author Email: LiuJie@ Yangtzeu.edu.cn

https://doi.org/10.18280/ijht.390231

Received: 8 October 2020

Accepted: 17 January 2021

\section{Keywords:}

rotary flow jetting tool (RFJT), rotary flow, orthogonal test design, drainage gas recovery, numerical simulation

\begin{abstract}
As gas-liquid passes through a rotary flow jetting tool (RFJT), both rotary and vortex flows will appear due to the structural features of the tool. In fact, the state of rotary and vortex flows is greatly affected by the structural parameters of the tool. Based on the principle of similitude, this paper establishes a simulation device for the gas-liquid two-phase flow of RFJT. Following the idea of orthogonal test, a series of RFJTs with different structural parameters were designed for indoor tests. During the tests, the authors observed the flow patterns of gas-liquid passing through the tools, compared the rotary flow heights and discharge volume of gas-liquid after leaving these tools, and optimized the structural parameters of the tools under different gas volumes. On this basis, the authors further analyzed how the change of a single structural parameter affects the gas-liquid flow state. The results show that a spiral body with 2.25 rings and a draft pipe of $25 \mathrm{~mm}$ in diameter can effectively realize gas-liquid separation, and create rotary flow, facilitating the effective delivery of liquid. Subsequently, several mathematical models were screened and verified for numerical simulation of RFJT. The results show that the Euler-Euler model is suitable for multiphase flow, and Reynolds stress model is suitable for turbulence. The mean error of simulation was merely $8.21 \%$, i.e., $91.97 \%$ of simulated results agree with test results.
\end{abstract}

\section{INTRODUCTION}

During the middle and late phases of gas well production, fluid often accumulates in the wellbore mainly for two reasons: On the one hand, the decline of reservoir energy makes it impossible to maintain the mist flow state in the wellbore; the relatively slow gas flow cannot carry the produced liquid to the wellhead. On the other hand, the wellbore pressure and temperature are not constant; instead, the two parameters drop more significantly as we get closer to the surface; thus, the condensate produced as the gas moves from the wellbore to the wellhead will fall back to the wellbore. Wellbore fluid accumulation hinders the production of the gas well. If this phenomenon lasts long, the gas well will be forced to shut down [1].

The first attempt to apply vortex flow jetting tool (VFJT) to drainage gas recovery was made by Vortex Flow Inc in 2002 [2]. Tests and field applications show that VFJT can reduce the pressure drop in the tubing, and slash the critical gas velocity for liquid carrying by up to $10 \%$ [3-5]. Since then, many scholars have applied VFJT to drainage gas recovery of gas wells, and discovered multiple advantages of VFJT [6-10]: reducing the critical gas velocity required for liquid carrying, improving recovery rate, low cost, easy to maintain, and wide applicability.

After years of development, a complete theoretical system has formed for jet pump design. In general, a jet pump mainly consists of a nozzle, a throat pipe, a diffusion pipe, a suction chamber, etc. [11]. The jet pump enhances the energy of the slow liquid being sucked with a fast jet, thereby increasing the overall pressure energy. As a result, the vortex acquires a faster tangential velocity, and thus separates gas-liquid two phases, reducing the energy loss. The combination of jet and vortex flows can effectively separate the fluid with two or more phases for transmission.

Currently, there are few reports on RFJT application in the wellbore of gas wells. Hence, this paper mainly optimizes the structural parameters of downhole RFJT, and analyzes the effects of different structural parameters on gas-liquid flow state. Besides, a turbulence model and a multiphase model were screened and verified for RFJT numerical simulation.

\section{DESIGN AND OPTIMIZATION OF RFJT STRUCTURAL PARAMETERS}

\subsection{Parameter design}

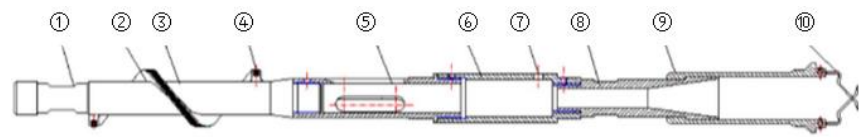

Figure 1. Assembly drawing of RFJT (1. Fishing head; 2. Spiral body; 3. Pitch diameter of spiral body; 4 . Wing; 5 .

Draft pipe; 6 . Throat pipe; 7 . Side holes of throat pipe; 8 . Jet sub; 9. Coupling clamp; 10 Spring)

According to the detailed structure parameters of downhole RFJT in the actual engineering drawings, the initial downhole RFJT was processed. Its structure is shown in Figure 1, and 
Figure 2 is the physical diagram of the jet swirl tool. Table 1 shows the structural parameters of downhole RFJT.

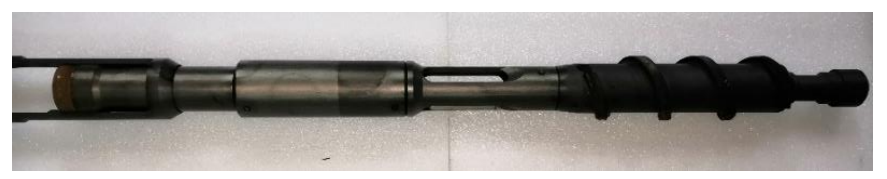

Figure 2. A photo of RFJT

Table 1. Basic structural parameters of RFJT

\begin{tabular}{|c|c|c|c|}
\hline Component & Parameter & Sign/Unit & Value \\
\hline \multirow{5}{*}{ Spiral body } & Pitch diameter & $\mathrm{D} 1 / \mathrm{mm}$ & 35 \\
\hline & Wing width & $\mathrm{L} 1 / \mathrm{mm}$ & 4 \\
\hline & Wing height & $\mathrm{H} 1 / \mathrm{mm}$ & 16.5 \\
\hline & $\begin{array}{l}\text { Effective number of } \\
\text { spiral turns }\end{array}$ & Each & 1.5 \\
\hline & Helix angle & $\theta_{1} /{ }^{\circ}$ & 45 \\
\hline \multirow{3}{*}{ Draft pipe } & Inner diameter & $\mathrm{D} 2 / \mathrm{mm}$ & 30 \\
\hline & Number of draft holes & Each & 3 \\
\hline & Inner diameter & $\mathrm{D} 3 / \mathrm{mm}$ & 38 \\
\hline \multirow[t]{2}{*}{ Throat pipe } & Number of side holes & Each & 3 \\
\hline & Side hole diameter & $\mathrm{D} 4 / \mathrm{mm}$ & 10 \\
\hline \multirow{4}{*}{ Nozzle } & Outlet diameter & $\mathrm{D} 5 / \mathrm{mm}$ & 20 \\
\hline & Throat-nozzle distance & $\mathrm{L} 2 / \mathrm{mm}$ & 30 \\
\hline & Inlet diameter & $\mathrm{D} 6 / \mathrm{mm}$ & 40 \\
\hline & $\begin{array}{l}\text { Contraction angle of } \\
\text { reducing section }\end{array}$ & $\theta_{2}{ }^{\circ}$ & 15 \\
\hline
\end{tabular}

\subsection{Parameter optimization}

\subsubsection{Simulation device}

Figures 3(a) and 3(b) present a photo and the simulation flow of our indoor simulation device, respectively. The simulation device is composed of the following parts: a gas supply system, a liquid supply system, a gas-liquid mixer, a plexiglass column system, a data acquisition system, and a gas-liquid separation tank.

A total of three pressure measuring points and one pressure drop point were arranged: the three pressure measuring points were deployed at the inlet of the tool, the outlet of the tool, and $5.7 \mathrm{~m}$ from the inlet, respectively; the differential pressure gauge starts from the second pressure measuring point, and ends at $10.5 \mathrm{~m}$ from the inlet, with a precision $(0.1)$ meeting the simulation requirements.

Every $0.002 \mathrm{~s}$, a real-time weighing device was adopted to weigh the liquid discharged to the wellhead. The weight of the liquid carried by each RFJT was derived from the weight of the discharged liquid. In the gas-liquid mixer, the gas and liquid phases were mixed with a patented instrument. This ensures that the two phases had been mixed, instead of remaining in discrete state, before entering the pipe, a prerequisite for the normal operation of RFJT. Meanwhile, an air volume of $2,400 \mathrm{~m}^{3} / \mathrm{d}$ was provided by the air compressor. The gas pressure entering the pipe was stabilized by the surge tank.

As shown in Figure 3, (a) is the indoor simulation device diagram; (b) is the flowchart of the indoor simulation experiment device. The indoor simulation experiment device is mainly composed of gas and liquid supply system, gasliquid mixer, plexiglass column system, data sensing and acquisition system, gas-liquid separation system and other main parts.

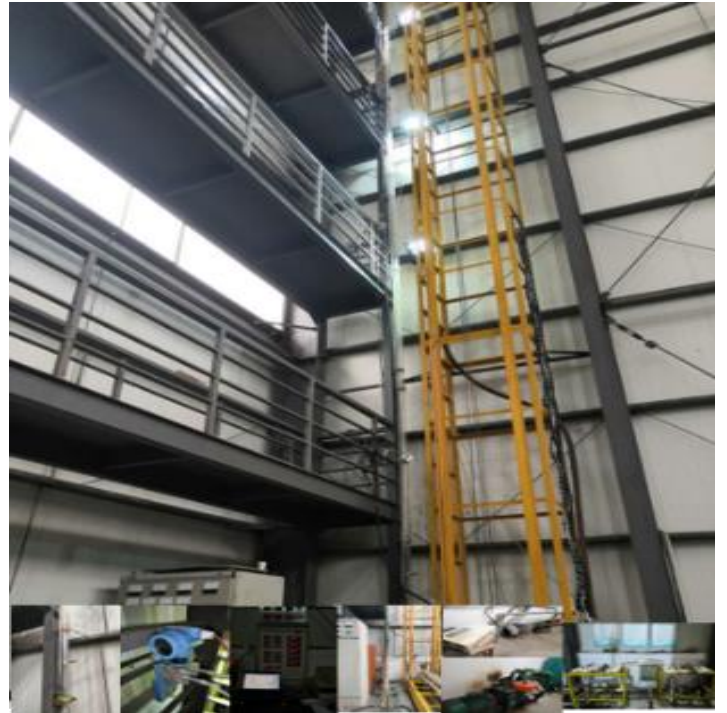

(a) Photo

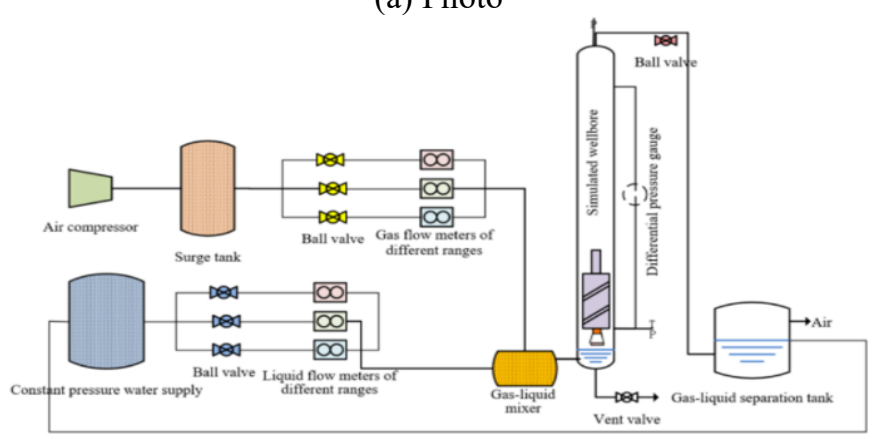

(b) Simulation flow

Figure 3. Test device

There are three pressure measuring points and one pressure drop point on the plexiglass string: the three pressure measuring points were deployed at the inlet of the tool, the outlet of the tool, and $5.7 \mathrm{~m}$ from the inlet, respectively; the differential pressure gauge starts from the second pressure measuring point, and ends at $10.5 \mathrm{~m}$ from the inlet, with a precision $(0.1)$ meeting the simulation requirements.

The wellhead drained fluid is measured by a real-time weighing device every $0.002 \mathrm{~s}$, and the weight of the wellhead carried by different RFJT can be obtained by using this device. The gas-liquid mixer is its own patented equipment, which can be used to mix the gas-liquid phases so that the gas-liquid phases entering the pipeline are mixed phases rather than discrete phases, ensuring full operation of the jet swirl tool. The air compressor can provide an air volume of $2400 \mathrm{~m} 3 / \mathrm{d}$. The surge tank has a voltage stabilizing effect, ensuring that the pressure of the gas entering the experimental pipeline does not fluctuate.

\subsubsection{Liquid discharge without tool}

To facilitate the evaluation of RFJT performance, the authors firstly tested the gas flow carrying the hydrostatic column without any tool. The test results are shown in Figure 4. When the gas volume was small, the gas velocity could not bring the liquid out of the wellbore; the gas-liquid two-phase flow in the wellbore mainly existed as a slug flow; the liquid was lifted by a certain distance, and then fell back obviously; after a while of falling, the liquid was lifted again, but not far enough to reach the outlet of the column. When the gas volume was medium, the gas flow could lift the liquid to a higher level, carrying part of the liquid out of the column; during the test, 
the gas-liquid flow mainly existed as a turbulence; meanwhile, a part of the liquid fell back in the lifting process. When the gas volume was large, the gas velocity was fast enough to fully carry all liquid out of the wellbore; in this case, an annular flow was observed in the column, with a gaseous core at the center; the liquid moved up along the column wall. The critical liquidcarrying gas flow had already been derived from the indoor test phenomena and the relevant calculation formula. On this basis, the minimum gas volume for normal liquid carrying under the test condition was obtained as $70 \mathrm{~m}^{3} / \mathrm{h}$. Hence, our liquid carrying test and RFJT evaluation test were carried out under three gas volumes: $60 \mathrm{~m}^{3} / \mathrm{h}, 70 \mathrm{~m}^{3} / \mathrm{h}$, and $80 \mathrm{~m}^{3} / \mathrm{h}$.

The data of the above test are recorded in Table 2 .

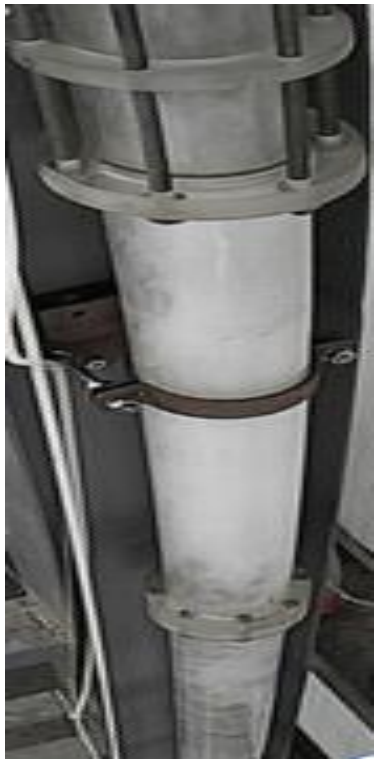

(a) Apparent falling of the liquid (slug flow)

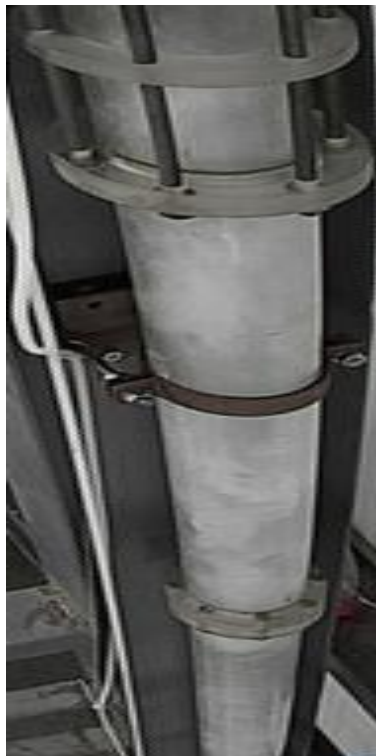

(b) Falling of part of the liquid (turbulence)

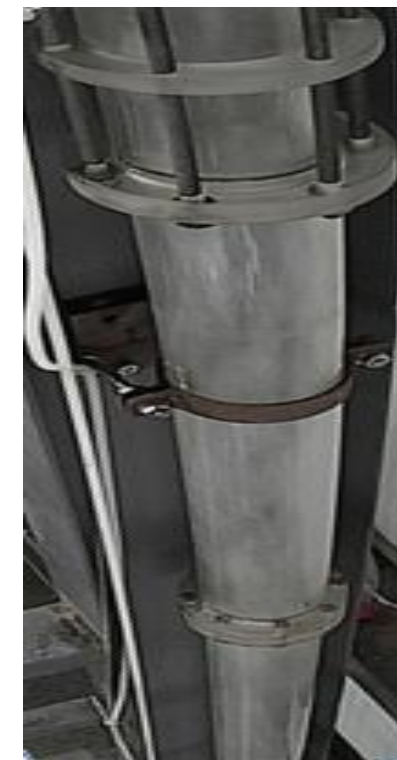

(c) Continuous liquid carrying (annular flow)

Figure 4. Gas-liquid two-phase flow patterns in the wellbore without any tool

Table 2. Test data on liquid carrying without any tool

\begin{tabular}{|c|c|c|c|c|c|c|}
\hline $\begin{array}{l}\text { Theoretical gas } \\
\text { volume }\left(\mathbf{m}^{3} / \mathbf{h}\right)\end{array}$ & $\begin{array}{c}\text { Pressure } \\
1 / K P a\end{array}$ & $\begin{array}{l}\text { Pressur } \\
\text { e } 2 / K P a\end{array}$ & $\begin{array}{l}\text { Pressur } \\
\text { e 3/KPa }\end{array}$ & $\begin{array}{c}\text { Pressure } \\
\text { difference } / K P a\end{array}$ & $\begin{array}{l}\text { Discharge } \\
\text { volume } / \mathrm{kg}\end{array}$ & $\begin{array}{c}\text { Flow pattern } \\
\text { in wellbore }\end{array}$ \\
\hline 60 & 11.28 & 8.38 & 5.57 & 2.22 & 0.13 & $\begin{array}{l}\text { 5m-high stirred flow at the lower part, with a } \\
\text { mist flow at the back }\end{array}$ \\
\hline 70 & 12.91 & 10.42 & 8.49 & 1.83 & 0.37 & $\begin{array}{l}7 \mathrm{~m} \text {-high stirred flow at the lower part, with a } \\
60 \mathrm{~m} \text {-long liquid at the back falling along the } \\
\text { wall }\end{array}$ \\
\hline 80 & 14.03 & 12.06 & 11.25 & 1.66 & 1.16 & Annular flow in the whole wellbore \\
\hline
\end{tabular}

\subsubsection{Orthogonal test design}

Our previous research shows that, for a VFJT, the optimal interval for the helix angle is $45-60^{\circ}$, and that for wing width, which determines the working distance of the tool, is $2-14 \mathrm{~mm}$ [12-14]. As for jet pump, Lu Hongqi [11] held that the optimal throat-nozzle distance should be 0.5-1 times the diameter of the throat pipe. However, the optimization of one of these structural parameters often leads to different tool performances. There are mainly two reasons for the difference: (1) The variation in test conditions; (2) The structural parameter being optimized is affected by the other structural parameters, which vary from tool to tool.

Referring to the structural parameters of jetting device and VFJT optimized by Guo Yannan for surface gas transmission pipeline [15], this paper chooses to optimize 7 structural parameters: number of side holes of throat pipe, throat pipe length, nozzle diameter, throat-nozzle distance, pitch diameter of spiral body, helix angle, and wing width. Two levels were designed for the number of side holes of throat pipe, and four levels for each of the other parameters, creating an L32 $\left(2^{1} 4^{7}\right)$ orthogonal design (Table 3 ). Table 4 shows the value of each parameter on each level. This design considers the interaction between structural parameters, and overcomes the defect of single-factor analysis.

\subsubsection{Test procedure}

Step 1. Load the RFJT.

Step 2. Close the gas flow control valve and the one-way valve to prevent liquid from entering the gas pipe; inject liquid to the test segment until the liquid reaches $30 \mathrm{~cm}$ from the mixer outlet.

Step 3. Close the liquid flow control valve and open the gas flow control valve, and test the liquid carrying ability of the gas at the gas volume of 60,70 , and $80 \mathrm{~m}^{3} / \mathrm{h}$, respectively.

Step 4 . Test the discharge volume and rotary flow height of the tools with different structural parameters at the gas volume of 60,70 , and $80 \mathrm{~m}^{3} / \mathrm{h}$, respectively, and record the wellbore pressures before and after loading the tool.

\subsubsection{Results and discussion}

Tables 5 and 6 show the results of the orthogonal test according to the above procedures and the L32 $\left(2^{1} 4^{7}\right)$ design in Table 3. 
Table 3. Orthogonal test design

\begin{tabular}{|c|c|c|c|c|c|c|c|c|}
\hline \multirow{2}{*}{ Level } & \multicolumn{8}{|c|}{$\operatorname{L32}\left(2^{1} 4^{7}\right)$} \\
\hline & $\begin{array}{c}\text { Number of side holes } \\
\text { of throat pipe }\end{array}$ & $\begin{array}{c}\text { Throat pipe } \\
\text { length }\end{array}$ & $\begin{array}{c}\text { Nozzle } \\
\text { diameter }\end{array}$ & $\begin{array}{c}\text { Throat-nozzle } \\
\text { distance }\end{array}$ & $\begin{array}{c}\text { Pitch } \\
\text { diameter }\end{array}$ & $\begin{array}{l}\text { Helix } \\
\text { angle }\end{array}$ & $\begin{array}{l}\text { Wing } \\
\text { width }\end{array}$ & $\begin{array}{l}\text { Null } \\
\text { term }\end{array}$ \\
\hline 1 & 1 & 1 & 1 & 1 & 1 & 1 & 1 & 1 \\
\hline 2 & 1 & 1 & 2 & 2 & 2 & 2 & 2 & 2 \\
\hline 3 & 1 & 1 & 3 & 3 & 3 & 3 & 3 & 3 \\
\hline 4 & 1 & 1 & 4 & 4 & 4 & 4 & 4 & 4 \\
\hline 5 & 1 & 2 & 1 & 1 & 2 & 2 & 3 & 3 \\
\hline 6 & 1 & 2 & 2 & 2 & 1 & 1 & 4 & 4 \\
\hline 7 & 1 & 2 & 3 & 3 & 4 & 4 & 1 & 1 \\
\hline 8 & 1 & 2 & 4 & 4 & 3 & 3 & 2 & 2 \\
\hline 9 & 1 & 3 & 1 & 2 & 3 & 4 & 1 & 2 \\
\hline 10 & 1 & 3 & 2 & 1 & 4 & 3 & 2 & 1 \\
\hline 11 & 1 & 3 & 3 & 4 & 1 & 2 & 3 & 4 \\
\hline 12 & 1 & 3 & 4 & 3 & 2 & 1 & 4 & 3 \\
\hline 13 & 1 & 4 & 1 & 2 & 4 & 3 & 3 & 4 \\
\hline 14 & 1 & 4 & 2 & 1 & 3 & 4 & 4 & 3 \\
\hline 15 & 1 & 4 & 3 & 4 & 2 & 1 & 1 & 2 \\
\hline 16 & 1 & 4 & 4 & 3 & 1 & 2 & 2 & 1 \\
\hline 17 & 2 & 1 & 1 & 4 & 1 & 4 & 2 & 3 \\
\hline 18 & 2 & 1 & 2 & 3 & 2 & 3 & 1 & 4 \\
\hline 19 & 2 & 1 & 3 & 2 & 3 & 2 & 4 & 1 \\
\hline 20 & 2 & 1 & 4 & 1 & 4 & 1 & 3 & 2 \\
\hline 21 & 2 & 2 & 1 & 4 & 2 & 3 & 4 & 1 \\
\hline 22 & 2 & 2 & 2 & 3 & 1 & 4 & 3 & 2 \\
\hline 23 & 2 & 2 & 3 & 2 & 4 & 1 & 2 & 3 \\
\hline 24 & 2 & 2 & 4 & 1 & 3 & 2 & 1 & 4 \\
\hline 25 & 2 & 3 & 1 & 3 & 3 & 1 & 2 & 4 \\
\hline 26 & 2 & 3 & 2 & 4 & 4 & 2 & 1 & 3 \\
\hline 27 & 2 & 3 & 3 & 1 & 1 & 3 & 4 & 2 \\
\hline 28 & 2 & 3 & 4 & 2 & 2 & 4 & 3 & 1 \\
\hline 29 & 2 & 4 & 1 & 3 & 4 & 2 & 4 & 2 \\
\hline 30 & 2 & 4 & 2 & 4 & 3 & 1 & 3 & 1 \\
\hline 31 & 2 & 4 & 3 & 1 & 2 & 4 & 2 & 4 \\
\hline 32 & 2 & 4 & 4 & 2 & 1 & 3 & 1 & 3 \\
\hline
\end{tabular}

Table 4. Value of each parameter on each level

\begin{tabular}{cccccccc}
\hline Factor & $\begin{array}{c}\text { Number of side holes of } \\
\text { throat pipe }\end{array}$ & $\begin{array}{c}\text { Throat pipe } \\
\text { length }\end{array}$ & $\begin{array}{c}\text { Nozzle } \\
\text { diameter }\end{array}$ & $\begin{array}{c}\text { Throat-nozzle } \\
\text { distance }\end{array}$ & $\begin{array}{c}\text { Pitch } \\
\text { diameter }\end{array}$ & $\begin{array}{c}\text { Helix } \\
\text { angle }\end{array}$ & $\begin{array}{c}\text { Wing } \\
\text { width }\end{array}$ \\
\hline 1 & 3 & 190 & 10 & 26 & 30 & 45 & 4 \\
2 & 4 & 209 & 15 & 30 & 35 & 50 & 6 \\
3 & & 228 & 20 & 34 & 40 & 55 & 8 \\
4 & 247 & 25 & 38 & 45 & 60 & 10 \\
\hline
\end{tabular}

Table 5. Discharge volume of different tools at different gas volumes

\begin{tabular}{|c|c|c|c|c|c|c|}
\hline Level & $\begin{array}{c}\text { Number of side holes of } \\
\text { throat pipe/each }\end{array}$ & $\begin{array}{l}\text { Throat pipe } \\
\text { length/mm }\end{array}$ & $\begin{array}{c}\begin{array}{c}\text { Nozzle } \\
\text { diameter/mm }\end{array} \\
\end{array}$ & $\begin{array}{l}\text { Throat-nozzle } \\
\text { distance } / \mathbf{m m}\end{array}$ & $\begin{array}{c}\text { Pitch } \\
\text { diameter/mm }\end{array}$ & $\begin{array}{c}\text { Helix } \\
\text { angle/ } /\end{array}$ \\
\hline 1 & 3 & 190 & 10 & 26 & 30 & 45 \\
\hline 2 & 3 & 190 & 15 & 30 & 35 & 50 \\
\hline 3 & 3 & 190 & 20 & 34 & 40 & 55 \\
\hline 4 & 3 & 190 & 25 & 38 & 45 & 60 \\
\hline 5 & 3 & 209 & 10 & 26 & 35 & 50 \\
\hline 6 & 3 & 209 & 15 & 30 & 30 & 45 \\
\hline 7 & 3 & 209 & 20 & 34 & 45 & 60 \\
\hline 8 & 3 & 209 & 25 & 38 & 40 & 55 \\
\hline 9 & 3 & 228 & 10 & 30 & 40 & 60 \\
\hline 10 & 3 & 228 & 15 & 26 & 45 & 55 \\
\hline 11 & 3 & 228 & 20 & 38 & 30 & 50 \\
\hline 12 & 3 & 228 & 25 & 34 & 35 & 45 \\
\hline 13 & 3 & 247 & 10 & 30 & 45 & 55 \\
\hline 14 & 3 & 247 & 15 & 26 & 40 & 60 \\
\hline 15 & 3 & 247 & 20 & 38 & 35 & 45 \\
\hline 16 & 3 & 247 & 25 & 34 & 30 & 50 \\
\hline 17 & 4 & 190 & 10 & 38 & 30 & 60 \\
\hline
\end{tabular}




\begin{tabular}{|c|c|c|c|c|c|c|}
\hline 18 & 4 & 190 & 15 & 34 & 35 & 55 \\
\hline 19 & 4 & 190 & 20 & 30 & 40 & 50 \\
\hline 20 & 4 & 190 & 25 & 26 & 45 & 45 \\
\hline 21 & 4 & 209 & 10 & 38 & 35 & 55 \\
\hline 22 & 4 & 209 & 15 & 34 & 30 & 60 \\
\hline 23 & 4 & 209 & 20 & 30 & 45 & 45 \\
\hline 24 & 4 & 209 & 25 & 26 & 40 & 50 \\
\hline 25 & 4 & 228 & 10 & 34 & 40 & 45 \\
\hline 26 & 4 & 228 & 15 & 38 & 45 & 50 \\
\hline 27 & 4 & 228 & 20 & 26 & 30 & 55 \\
\hline 28 & 4 & 228 & 25 & 30 & 35 & 60 \\
\hline 29 & 4 & 247 & 10 & 34 & 45 & 50 \\
\hline 30 & 4 & 247 & 15 & 38 & 40 & 45 \\
\hline 31 & 4 & 247 & 20 & 26 & 35 & 60 \\
\hline 32 & 4 & 247 & 25 & 30 & 30 & 55 \\
\hline
\end{tabular}

Table 5. Discharge volume of different tools at different gas volumes (continued)

\begin{tabular}{|c|c|c|c|c|c|}
\hline Level & $\begin{array}{c}\text { Wing } \\
\text { width/mm }\end{array}$ & $\begin{array}{l}\text { Null } \\
\text { term }\end{array}$ & $\begin{array}{c}\text { Gas volume } 60 \mathrm{~m}^{3} / \mathrm{h} \\
\text { Discharge volume } / \mathrm{kg}\end{array}$ & $\begin{array}{c}\text { Gas volume } 70 \mathrm{~m}^{3} / \mathrm{h} \\
\text { Discharge volume } / \mathrm{kg}\end{array}$ & $\begin{array}{c}\text { Gas volume } 80 \mathrm{~m}^{3} / \mathrm{h} \\
\text { Discharge volume } / \mathrm{kg}\end{array}$ \\
\hline 1 & 4 & 1 & 0.053 & 0.84 & 1.88 \\
\hline 2 & 6 & 2 & 0.08 & 0.54 & 1.59 \\
\hline 3 & 8 & 3 & 0.08 & 0.35 & 1.43 \\
\hline 4 & 10 & 4 & 0.56 & 1.56 & 3.1 \\
\hline 5 & 8 & 4 & 0.09 & 0.73 & 2.01 \\
\hline 6 & 10 & 3 & 0.22 & 0.73 & 1.68 \\
\hline 7 & 4 & 2 & 0.5 & 1.5 & 2.9 \\
\hline 8 & 6 & 1 & 0.62 & 0.81 & 1.74 \\
\hline 9 & 4 & 3 & 0.09 & 0.75 & 1 \\
\hline 10 & 6 & 4 & 0.49 & 1 & 1.84 \\
\hline 11 & 8 & 1 & 0.18 & 0.54 & 1.44 \\
\hline 12 & 10 & 2 & 0.31 & 0.62 & 1.65 \\
\hline 13 & 8 & 2 & 0.23 & 0.86 & 2.08 \\
\hline 14 & 10 & 1 & 0.22 & 0.71 & 1.86 \\
\hline 15 & 4 & 4 & 0.22 & 0.65 & 2.91 \\
\hline 16 & 6 & 3 & 0.57 & 1.22 & 1.87 \\
\hline 17 & 6 & 2 & 0.19 & 0.86 & 2.03 \\
\hline 18 & 4 & 1 & 0.2 & 0.71 & 1.71 \\
\hline 19 & 10 & 4 & 0.04 & 0.48 & 2.21 \\
\hline 20 & 8 & 3 & 0.12 & 0.96 & 2.16 \\
\hline 21 & 10 & 3 & 0.33 & 0.51 & 1.94 \\
\hline 22 & 8 & 4 & 0.37 & 0.84 & 1.51 \\
\hline 23 & 6 & 1 & 0.32 & 0.75 & 2.09 \\
\hline 24 & 4 & 2 & 0.29 & 1.06 & 1.77 \\
\hline 25 & 6 & 4 & 0.26 & 0.55 & 1.97 \\
\hline 26 & 4 & 3 & 0.28 & 0.92 & 2.03 \\
\hline 27 & 10 & 2 & 0.11 & 0.74 & 1.46 \\
\hline 28 & 8 & 1 & 0.28 & 0.84 & 1.97 \\
\hline 29 & 10 & 1 & 0.32 & 1.3 & 2.16 \\
\hline 30 & 8 & 2 & 0.19 & 0.47 & 2.11 \\
\hline 31 & 6 & 3 & 0.19 & 0.65 & 2 \\
\hline 32 & 4 & 4 & 0.34 & 1.47 & 2.49 \\
\hline
\end{tabular}

Table 6. Rotary flow height produced by different tools at different gas volumes

\begin{tabular}{|c|c|c|c|c|c|c|}
\hline Level & $\begin{array}{c}\text { Number of side holes of } \\
\text { throat pipe/each }\end{array}$ & $\begin{array}{l}\text { Throat pipe } \\
\text { length } / \mathrm{mm}\end{array}$ & $\begin{array}{c}\text { Nozzle } \\
\text { diameter/mm }\end{array}$ & $\begin{array}{l}\text { Throat-nozzle } \\
\text { distance/mm }\end{array}$ & $\begin{array}{c}\text { Pitch } \\
\text { diameter } / \mathbf{m m}\end{array}$ & $\begin{array}{c}\text { Helix } \\
\text { angle } /{ }^{\circ}\end{array}$ \\
\hline 1 & 3 & 190 & 10 & 26 & 30 & 45 \\
\hline 2 & 3 & 190 & 15 & 30 & 35 & 50 \\
\hline 3 & 3 & 190 & 20 & 34 & 40 & 55 \\
\hline 4 & 3 & 190 & 25 & 38 & 45 & 60 \\
\hline 5 & 3 & 209 & 10 & 26 & 35 & 50 \\
\hline 6 & 3 & 209 & 15 & 30 & 30 & 45 \\
\hline 7 & 3 & 209 & 20 & 34 & 45 & 60 \\
\hline 8 & 3 & 209 & 25 & 38 & 40 & 55 \\
\hline 9 & 3 & 228 & 10 & 30 & 40 & 60 \\
\hline 10 & 3 & 228 & 15 & 26 & 45 & 55 \\
\hline 11 & 3 & 228 & 20 & 38 & 30 & 50 \\
\hline 12 & 3 & 228 & 25 & 34 & 35 & 45 \\
\hline 13 & 3 & 247 & 10 & 30 & 45 & 55 \\
\hline
\end{tabular}




\begin{tabular}{|c|c|c|c|c|c|c|}
\hline 14 & 3 & 247 & 15 & 26 & 40 & 60 \\
\hline 15 & 3 & 247 & 20 & 38 & 35 & 45 \\
\hline 16 & 3 & 247 & 25 & 34 & 30 & 50 \\
\hline 17 & 4 & 190 & 10 & 38 & 30 & 60 \\
\hline 18 & 4 & 190 & 15 & 34 & 35 & 55 \\
\hline 19 & 4 & 190 & 20 & 30 & 40 & 50 \\
\hline 20 & 4 & 190 & 25 & 26 & 45 & 45 \\
\hline 21 & 4 & 209 & 10 & 38 & 35 & 55 \\
\hline 22 & 4 & 209 & 15 & 34 & 30 & 60 \\
\hline 23 & 4 & 209 & 20 & 30 & 45 & 45 \\
\hline 24 & 4 & 209 & 25 & 26 & 40 & 50 \\
\hline 25 & 4 & 228 & 10 & 34 & 40 & 45 \\
\hline 26 & 4 & 228 & 15 & 38 & 45 & 50 \\
\hline 27 & 4 & 228 & 20 & 26 & 30 & 55 \\
\hline 28 & 4 & 228 & 25 & 30 & 35 & 60 \\
\hline 29 & 4 & 247 & 10 & 34 & 45 & 50 \\
\hline 30 & 4 & 247 & 15 & 38 & 40 & 45 \\
\hline 31 & 4 & 247 & 20 & 26 & 35 & 60 \\
\hline 32 & 4 & 247 & 25 & 30 & 30 & 55 \\
\hline
\end{tabular}

Table 6. Rotary flow height produced by different tools at different gas volumes (continued)

\begin{tabular}{|c|c|c|c|c|c|}
\hline Level & $\begin{array}{c}\text { Wing } \\
\text { width/mm }\end{array}$ & $\begin{array}{l}\text { Null } \\
\text { term }\end{array}$ & $\begin{array}{c}\text { Gas volume } 60 \mathrm{~m}^{3} / \mathrm{h} \\
\text { Discharge volume } / \mathrm{kg}\end{array}$ & $\begin{array}{c}\text { Gas volume } 70 \mathrm{~m}^{3} / \mathrm{h} \\
\text { Discharge volume } / \mathrm{kg}\end{array}$ & $\begin{array}{c}\text { Gas volume } 80 \mathrm{~m}^{3} / \mathrm{h} \\
\text { Discharge volume } / \mathrm{kg}\end{array}$ \\
\hline 1 & 4 & 1 & 0 & 0 & 1.8 \\
\hline 2 & 6 & 2 & 0 & 0.7 & 4 \\
\hline 3 & 8 & 3 & 0 & 0 & 1.3 \\
\hline 4 & 10 & 4 & 0.2 & 0.6 & 4.5 \\
\hline 5 & 8 & 4 & 0.1 & 0.15 & 3.6 \\
\hline 6 & 10 & 3 & 0.08 & 0.2 & 2.1 \\
\hline 7 & 4 & 2 & 0.1 & 0.55 & 4 \\
\hline 8 & 6 & 1 & 0.1 & 0.25 & 3.2 \\
\hline 9 & 4 & 3 & 0.2 & 0.3 & 2.8 \\
\hline 10 & 6 & 4 & 0.3 & 0.7 & 3.6 \\
\hline 11 & 8 & 1 & 0 & 0 & 1 \\
\hline 12 & 10 & 2 & 0 & 0.1 & 1.2 \\
\hline 13 & 8 & 2 & 0.2 & 0.3 & 3.6 \\
\hline 14 & 10 & 1 & 0.5 & 0.3 & 2.2 \\
\hline 15 & 4 & 4 & 0.05 & 0.55 & 3.8 \\
\hline 16 & 6 & 3 & 0.2 & 0.35 & 2.9 \\
\hline 17 & 6 & 2 & 0.15 & 0.3 & 0.4 \\
\hline 18 & 4 & 1 & 0.1 & 0.2 & 1.6 \\
\hline 19 & 10 & 4 & 0.1 & 0.3 & 3.6 \\
\hline 20 & 8 & 3 & 0.4 & 1 & 4.7 \\
\hline 21 & 10 & 3 & 0.2 & 0.35 & 3.6 \\
\hline 22 & 8 & 4 & 0.1 & 0.4 & 2 \\
\hline 23 & 6 & 1 & 0.3 & 1 & 4 \\
\hline 24 & 4 & 2 & 0.2 & 0.4 & 2 \\
\hline 25 & 6 & 4 & 0.1 & 0.2 & 4.8 \\
\hline 26 & 4 & 3 & 0.2 & 1 & 3.5 \\
\hline 27 & 10 & 2 & 0 & 0.25 & 1 \\
\hline 28 & 8 & 1 & 0.2 & 0.35 & 0.75 \\
\hline 29 & 10 & 1 & 0.15 & 1.5 & 5.3 \\
\hline 30 & 8 & 2 & 0.1 & 1.2 & 3.5 \\
\hline 31 & 6 & 3 & 0.1 & 0.2 & 1.4 \\
\hline 32 & 4 & 4 & 0.05 & 0.15 & 2.6 \\
\hline
\end{tabular}

Table 7. Optimal structural parameters of the RFJT

\begin{tabular}{ccccccccc}
\hline Indices & $\begin{array}{c}\text { Test gas } \\
\text { volume } \\
\boldsymbol{m}^{\mathbf{3} / \boldsymbol{h}}\end{array}$ & $\begin{array}{c}\text { Number of side } \\
\text { holes of throat } \\
\text { pipe/each }\end{array}$ & $\begin{array}{c}\text { Throat } \\
\text { pipe } \\
\text { length/mm }\end{array}$ & $\begin{array}{c}\text { Nozzle } \\
\text { diameter/mm }\end{array}$ & $\begin{array}{c}\text { Throat- } \\
\text { nozzle } \\
\text { distance/mm }\end{array}$ & $\begin{array}{c}\text { Pitch } \\
\text { diameter/mm }\end{array}$ & $\begin{array}{c}\text { Helix } \\
\text { angle/ }\end{array}$ & $\begin{array}{c}\text { Wing } \\
\text { width/mm }\end{array}$ \\
\hline Discharge & 60 & 3 & 247 & 10 & 38 & 45 & 55 & 10 \\
volume & 70 & 4 & 247 & 15 & 38 & 45 & 50 & 6 \\
Rotary & 80 & 4 & 247 & 15 & 26 & 35 & 60 & 6 \\
flow & 60 & 4 & 247 & 25 & 38 & 45 & 60 & 4 \\
height & 70 & 3 & 247 & 25 & 34 & 45 & 60 & 4 \\
\hline
\end{tabular}


According to the above results, discharge volume and rotary flow height were taken as the evaluation indices for range analysis. Table 7 shows the optimal structure parameters for different evaluation indices under different gas volumes. To balance discharge volume with rotary flow height, the optimal structural parameters of the RFJT are as follows: number of side holes of throat pipe $=3$, throat pipe length $=247 \mathrm{~mm}$, nozzle diameter $=25 \mathrm{~mm}$, throat-nozzle distance $=38 \mathrm{~mm}$, pitch diameter $=45 \mathrm{~mm}$, helix angle $=50^{\circ}-60^{\circ}$, and wing width $=4-6 \mathrm{~mm}$.

Next, the RFJT structure was optimized with the number of side holes of throat pipe $=3$, throat pipe length $=247 \mathrm{~mm}$, nozzle diameter $=25 \mathrm{~mm}$, throat-nozzle distance $=38 \mathrm{~mm}$, pitch diameter $=45 \mathrm{~mm}$, helix angle $=60^{\circ}$, and wing width $=$ $4 \mathrm{~mm}$. Following the same test procedure, another test was carried out on the optimized RFJT. Under the gas volume of 60,70 , and $80 \mathrm{~m}^{3} / \mathrm{h}$, the optimized RFJT achieved a discharge volume of $1.69 \mathrm{~kg}, 1.79 \mathrm{~kg}$, and $3.46 \mathrm{~kg}$, respectively, which is better than that achieved by any tool in the orthogonal design. In addition, the optimized RFJT produced a good rotary flow pattern (Figure 5). After leaving the tool, the liquid spiraled up along the wall, while the gas moved at a high speed at the center of the column in the form of an air column; with the growth of gas flow, the distance of the spiral up-flow along the wall increased; after the rotary flow used up its energy, a turbulence appeared in the column (Figure 6).

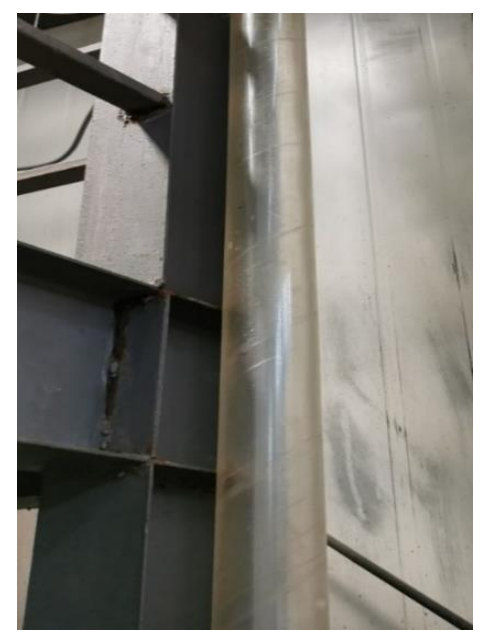

Figure 5. Rotary flow through the tool

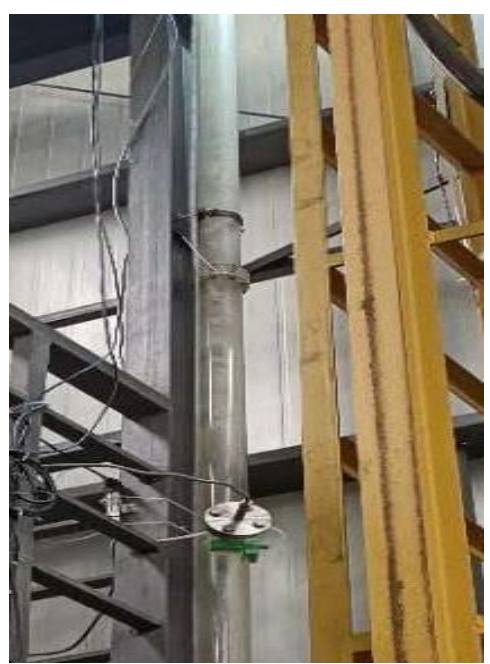

Figure 6. Transition zone between rotary flow and turbulence

\subsection{Influence of different structural parameters on gas- liquid flow state}

\subsubsection{Influence of number of spiral turns}

Taking the number of side holes of throat pipe $=3$, throat pipe length $=247 \mathrm{~mm}$, nozzle diameter $=25 \mathrm{~mm}$, and throatnozzle distance $=38 \mathrm{~mm}$ as the basic parameters, the authors carried out an analysis with the number of spiral turns as the single variable. Six spiral bodies were designed with different number of spiral turns: 1, 1.25,1.5, 1.75, 2 and 2.25, but with the same values for the following parameters: pitch diameter $=45 \mathrm{~mm}$, helix angle $=60^{\circ}$, and wing width $=4 \mathrm{~mm}$. On this basis, the fluid flow was tested, and the results are reported in Figures 7 and 8.

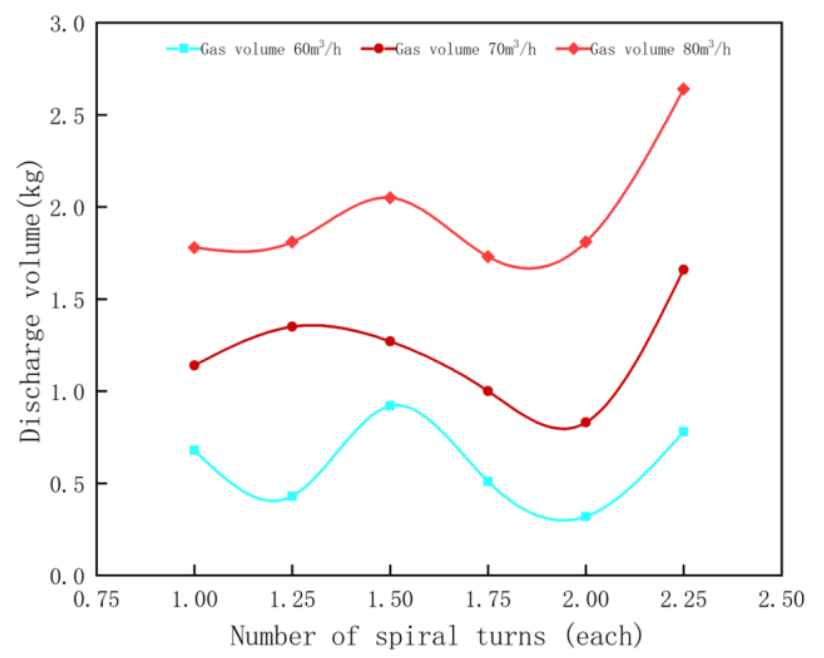

Figure 7. Influence of the number of spiral turns on discharge volume

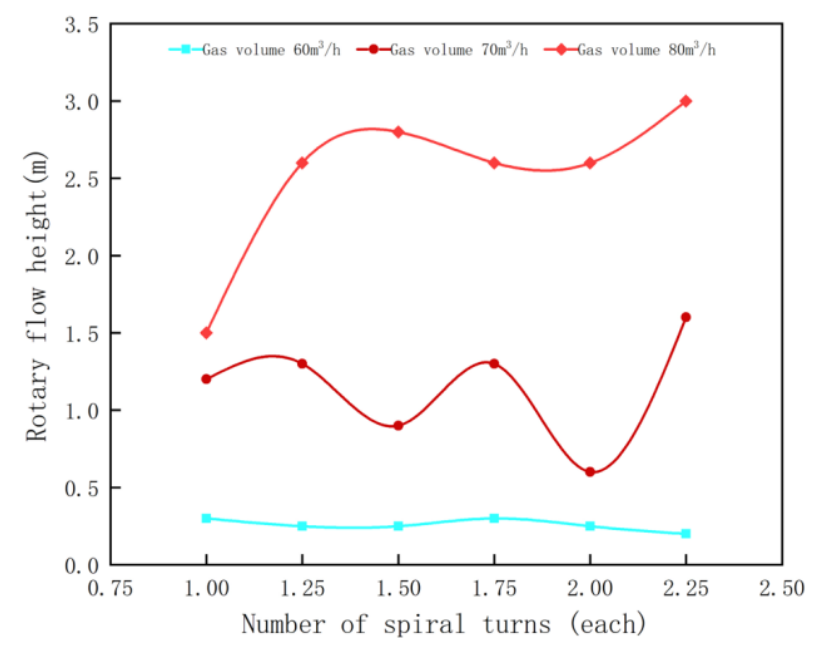

Figure 8. Influence of the number of spiral turns on rotary flow height

As shown in Figure 7, the discharge volume was relatively high, when the initial and final angles of the spiral body differed by $180^{\circ}$. With the addition of 1 spiral turn, the discharge volume increased accordingly. Judging by the influence of the number of spiral turns on discharge volume, it is recommended to adopt a spiral body with 2.25 turns. The influence of the number of spiral turns on rotary flow height (Figure 8 ) implies a good rotary flow height corresponding to 2.25 turns. 


\subsubsection{Influence of draft pipe diameter on flow state}

Here, the RFJT structure was optimized with the number of side holes of throat pipe $=3$, throat pipe length $=247 \mathrm{~mm}$, nozzle diameter $=25 \mathrm{~mm}$, throat-nozzle distance $=38 \mathrm{~mm}$, pitch diameter $=45 \mathrm{~mm}$, helix angle $=60^{\circ}$, and wing width $=$ $4 \mathrm{~mm}$. Then, draft pipes with three different diameters were designed: $20 \mathrm{~mm}, 25 \mathrm{~mm}$, and $30 \mathrm{~mm}$, and adopted for fluid flow test. The test results are recorded in Figures 9 and 10.

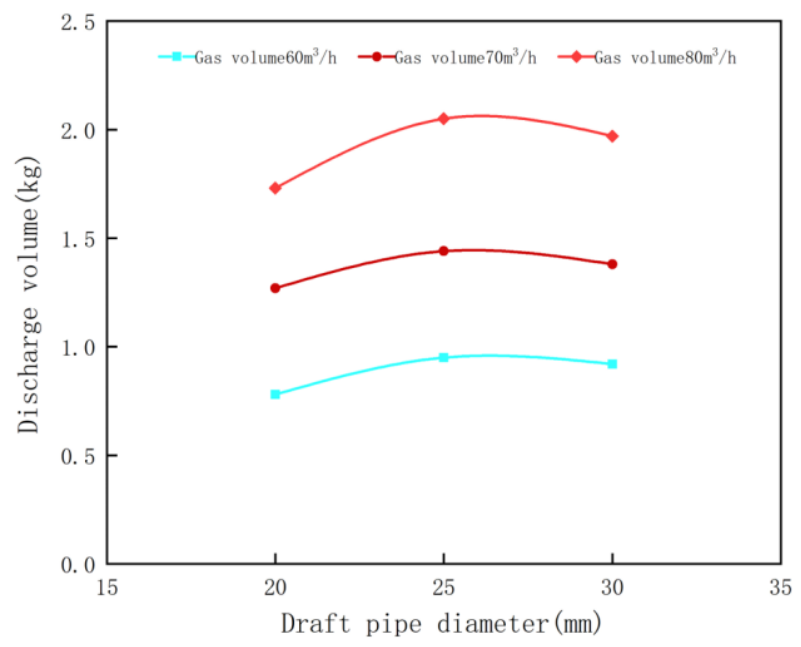

Figure 9. Influence of draft pipe diameter on discharge volume

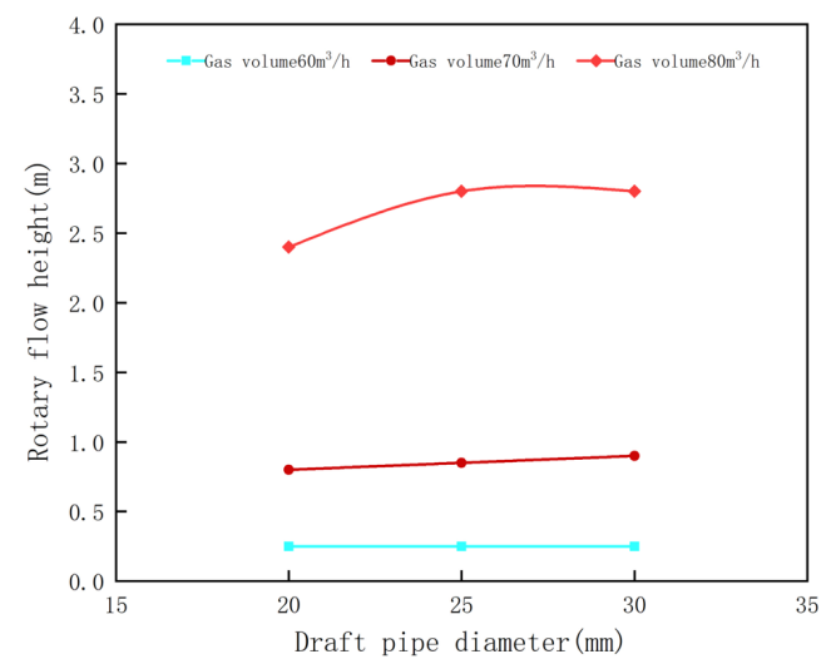

Figure 10. Influence of draft pipe diameter on rotary flow height

As shown in Figures 9 and 10, the discharge volume was relatively high when the draft pipe was of the diameter $25 \mathrm{~mm}$; this diameter also corresponded to a good rotary flow height. Therefore, the draft pipe diameter is recommended to be $25 \mathrm{~mm}$.

\section{SELECTION AND VERIFICATION OF MATHEMATICAL MODEL}

\subsection{Model construction and grid division}

Based on the RFJT structural parameters optimized above, a three-dimensional (3D) model was created for the RFJT on SolidWorks. The specific structure of the model is presented in Figure 11. Based on the 3D model, Boolean operation was performed to extract the fluid domain of the RFJT, and Meshing was adopted to divide the tool into structured grids. Note that some complex local parts were divided into unstructured grids, as shown in Figure 12.

Figure 13 is the grid quality inspection diagram. The grids were mainly distributed at around 0.25 , with a standard deviation of 0.16 and a maximum smaller than 0.9 . The grids were smooth and within the target skewness. The high-quality grids obviously meet the simulation requirements.

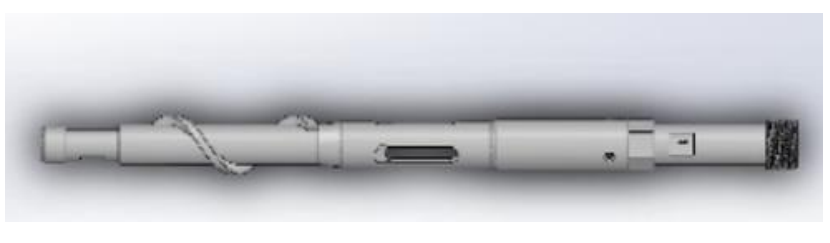

Figure 11. Diagram of RFJT model

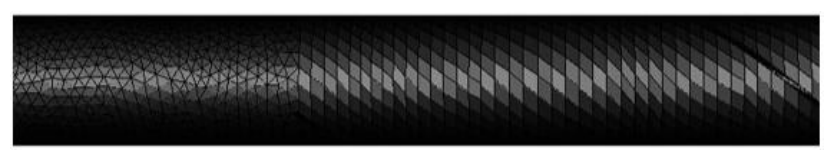

Figure 12. Unstructured grids in local parts

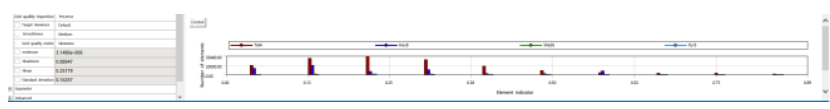

Figure 13. Grid quality inspection diagram

\subsection{Configuration of boundary conditions}

Air and water were set as the fluid. The inlet boundary condition was configured according to the indoor test condition with a flow of $60 \mathrm{~m}^{3} / \mathrm{h}$. The outlet boundary was treated as a pressure boundary, using the standard wall function. The relaxation factor was set to 0.3. The model was solved by the Semi-Implicit Method for Pressure Linked Equations (SIMPLE) algorithm. The different terms of the relaxation factor were configured as $0.3,1,1,0.3,0.1,0.3,0.3$, 0.4 , and 0.5 .

\subsection{Selection of multiphase flow models}

The model for gas-liquid two-phase flow mainly depends on the flow pattern of the gas phase, the volume fraction of the gas, and the gas distribution in the liquid. Generally, the volume of fluid (VOF) model applies to flow patterns like slug flow, stratified flow, and free flow surface. For bubble flow, the VOF model is usually adopted to simulate large bubbles, while hybrid model or Euler model is often selected for a group of small or micro bubbles, provided that the volume fraction of discrete bubbles is greater than $10 \%$.

Downhole RFJT is mainly used for drainage gas recovery in gas wells. In this task, the liquid is mostly carried out by the gas. Hence, gas is the primary phase, and liquid is the secondary phase. During downhole movement, the gas phase and liquid phase are not clearly stratified, but belong to the mixed state. Therefore, the VOF model is not suitable for numerical simulation of RFJT. The feasible alternatives include hybrid model and Euler-Euler model.

To screen and verify turbulence model, the key lies in the precision of multiphase model. The higher the precision, the 
better. To select a desirable turbulence model, this paper chooses the Euler-Euler model, which is more precise than the hybrid model.

Euler-Euler model processes each term by Euler's method. Assuming that all terms share the same pressure, the model solves the continuity and momentum equations of each term. In the Euler model, only one phase is designated as the particle phase, without differentiating between fluid-fluid multiphase flow and fluid-solid (particle) multiphase flow.

There are four basic hypotheses of the Euler model: (1) The fluid is incompressible, and all terms share the same pressure field; (2) The continuity and momentum equations are solved for each term; (3) The transfer of inter-phase momentum is modeled with the inter-phase drag synergy function, which characterizes the local inter-phase slip velocity; (4) The turbulence of each term is modelled independently.

\subsubsection{Volume fraction}

The multiphase flow is a continuum, in which different phases are interspersed. The phase volume fraction was introduced to describe such a continuum. The volume fraction represents the space occupied by each phase, which independently meets the laws of conservation of mass and momentum. The conservation equations could be derived by adding up or mixing the instantaneous equilibria of each phase in different local areas.

Let $\alpha_{q}$ be the volume fraction of phase q. Then, the volume of phase q can be defined as:

$$
V_{q}=\int_{V} \alpha_{q} d V
$$

where,

$$
\sum_{q=1}^{n} \alpha_{q}=1
$$

The effective density of phase $\mathrm{q}$ can be expressed as:

$$
\hat{\rho}_{q}=\alpha_{q} \rho_{q}
$$

\subsubsection{Conservation equations}

(1) Conservation equation of mass

The continuity equation of phase $q$ can be defined as:

$$
\begin{aligned}
& \frac{\partial}{\partial t}\left(\alpha_{q} \rho_{q}\right)+\nabla \cdot\left(\alpha_{q} \rho_{q} \overrightarrow{v_{q}}\right) \\
& =\sum_{p=1}^{n}\left(\dot{m}_{q p}-\dot{m}_{p q}\right)+S_{q}
\end{aligned}
$$

where, $\vec{V}$ is the velocity of phase $q ; \dot{m}_{q p}$ is the mass transfer from phase $q$ to phase $\mathrm{p} ; \dot{\mathrm{m}}_{\mathrm{pq}}$ is the mass transfer from phase $p$ to phase $q$ (the mass transfer mechanism can be specified separately); $S_{q}$ is a source term, which can be set to the default of zero, defined as a constant, or defined by the user.

The volume fraction of each phase can be solved by the continuity equation:

$$
\begin{gathered}
\frac{1}{\rho_{r q}}\left[\frac{\partial}{\partial t}\left(\alpha_{q} \rho_{q}\right)+\nabla \cdot\left(\alpha_{q} \rho_{q} \vec{v}_{q}\right)\right] \\
=\sum_{p=1}^{n}\left(\dot{m}_{q p}-\dot{m}_{p q}\right)
\end{gathered}
$$

where, $\rho_{r q}$ is the reference density of the phase, i.e., the mean volume density of phase $\mathrm{q}$ in the computational domain. The volume fraction of the basic phase is constrained by the requirement that the sum of the volume fractions of all phases must equal 1. This constraint applies to both fluid-fluid multiphase flow and fluid-solid multiphase flow.

(2) Conservation equation of momentum

The momentum equation of phase $\mathrm{q}$ can be defined as:

$$
\begin{gathered}
\frac{\partial}{\partial t}\left(\alpha_{q} \rho_{q} \overrightarrow{v_{q}}\right)+\nabla \cdot\left(\alpha_{q} \rho_{q} \vec{v}_{q} \vec{v}_{q}\right)=-\alpha_{q} \nabla p+\nabla \cdot \overline{\bar{\tau}}_{q} \\
+\alpha_{q} \rho_{q} \vec{g}+\sum_{p=1}^{n}\left(\vec{R}_{p q}+\dot{m}_{p q} \vec{v}_{p q}-\dot{m}_{q p} \vec{v}_{q p}\right) \\
+\left(\vec{F}_{q}+\vec{F}_{l i f t, q}+\vec{F}_{v m, q}\right)
\end{gathered}
$$

where, $\vec{g}$ is the acceleration of gravity; $\overline{\bar{\tau}}$ is the stress-strain tensor of phase $q$ :

$$
\overline{\bar{\tau}}_{q}=\alpha_{q} \mu_{q}\left(\nabla \vec{v}_{q}+\vec{v}_{q}^{T}\right)+\alpha_{q}\left(\lambda_{q}-\frac{2}{3} \mu_{q}\right) \nabla \cdot \vec{v}_{q} \overline{\bar{I}}
$$

where, $\mu_{q}$ and $\lambda_{q}$ are the shear adhesive coefficient and volume adhesive coefficient of phase q, respectively; $\vec{F}_{q}$ is the external volume force; $\vec{F}_{l i f t, q}$ is the lift force; $\vec{F}_{v m, q}$ is the virtual mass force; $\overrightarrow{\mathrm{R}}_{\mathrm{pq}}$ is the interphase interaction; $\mathrm{P}$ is the shared pressure by all phases; $\vec{v}_{p q}$ is the phase velocity:

If $\dot{m}_{p q}>0$ (i.e., mass transfers from phase $p$ to phase q), then $\vec{v}_{p q}=\vec{v}_{p}$

If $\dot{m}_{p q}<0$ (i.e., mass transfers from phase $q$ to phase $\mathrm{p}$ ), then $\vec{v}_{p q}=\vec{v}_{q}$.

Formula (7) needs to be closed by selecting a suitable interphase interaction $\vec{R}_{p q}$. The interphase interaction is associated with effects of friction, pressure, and adhesion, and in line with the conditions $\vec{R}_{p q}=-\vec{R}_{q p}$ and $\vec{R}_{q q}=0$.

$$
\sum_{p=1}^{n} \vec{R}_{p q}=\sum_{p=1}^{n} K_{p q}\left(\vec{v}_{p}-\vec{v}_{q}\right)
$$

where, $K_{p q}=K_{q p}$ is the interphase momentum exchange coefficient.

\subsection{Screening and verification of turbulence models}

\subsubsection{Screening of turbulence models}

Among the turbulence models provided by FLUENT, only $\mathrm{k}-\varepsilon$ model and Reynolds stress model apply to the numerical simulation of the RFJT. The k- $\varepsilon$ model encompasses three submodels: standard k- $\varepsilon$ model, Re-Normalization Group (RNG) $\mathrm{k}-\varepsilon$ model, and $\mathrm{k}-\varepsilon$ model with rotary flow. The standard $\mathrm{k}-\varepsilon$ model is only applicable to pure turbulence flow fields, as it assumes that the flow field only consists of turbulence, with negligible molecular adhesion. RNG k- $\varepsilon$ model performs well in some flows, thanks to its good response to transient flow and streamline bending. The $\mathrm{k}-\varepsilon$ model with rotary flow provides a universal simulation tool for various flows, including uniform shear rotary flow, jet flow, hybrid flow, channel flow, boundary flow, and separated flow. It is easy to see that the latter two k- $\varepsilon$ models are more suitable for our research.

The RNG k- $\varepsilon$ model, k- $\varepsilon$ model with rotary flow, and Reynolds stress model were separately adopted to simulate the RFJT with the optimal structural parameters, under the same gas volumes as the indoor test: $60 \mathrm{~m}^{3} / \mathrm{h}, 70 \mathrm{~m}^{3} / \mathrm{h}$, and $80 \mathrm{~m}^{3 /} \mathrm{h}$. The pipe segment for simulation was as long as that for the indoor test. Two pressure monitoring points (\#1 and 2\#) were set up at the same coordinates as those of the indoor test to obtain the pressure difference of the fluid before and after passing through the tool (hereinafter referred to as the pressure 
difference for short). Then, these turbulence models were verified by comparing the simulated pressure difference of the tool with the measured pressure difference (Table 8).

Table 8. Measured pressure difference of the tool (indoor test)

\begin{tabular}{cccc}
\hline Gas volume $\left(\mathrm{m}^{3} / \mathrm{h}\right)$ & 60 & 70 & 80 \\
\hline Measured pressure difference $(\mathrm{KPa})$ & 4.18 & 5.38 & 5.95 \\
\hline
\end{tabular}

Figure 14 presents the residual of RSM model at the gas flow of $60 \mathrm{~m}^{3} / \mathrm{h}$. In the upper part of the figure, the residual curve fell between 0.0001 and 0.001 , and had a good convergence. Table 9 lists the simulated results of the three turbulence models at the gas flows of $60 \mathrm{~m}^{3} / \mathrm{h}, 70 \mathrm{~m}^{3} / \mathrm{h}$, and $80 \mathrm{~m}^{3} / \mathrm{h}$. Under different gas flows, the Reynolds stress model achieved the best results, with a small error, and a high precision.
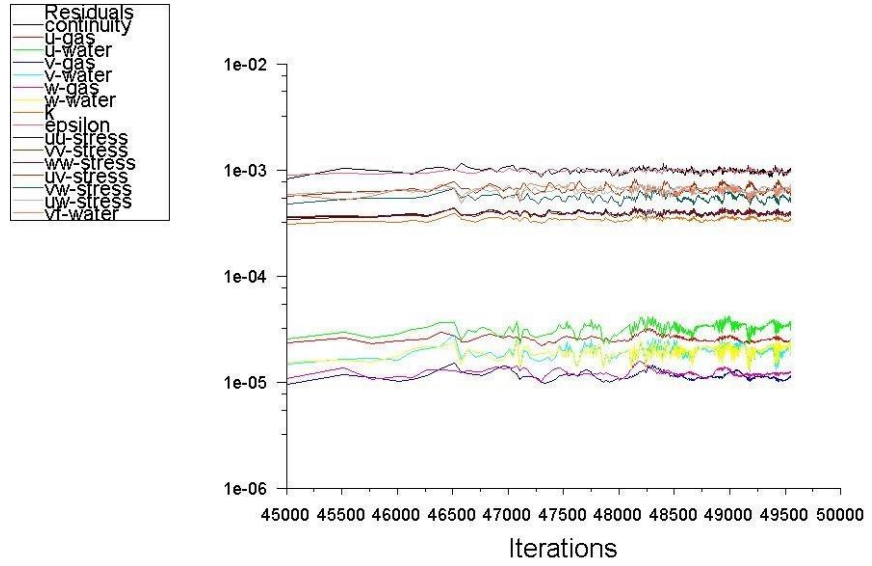

Figure 14. Residual of RSM model at the gas flow of $60 \mathrm{~m}^{3} / \mathrm{h}$

Table 9. Comparison between the simulated results of the three turbulence models at different gas flows and measured results

\begin{tabular}{|c|c|c|c|c|c|c|}
\hline \multirow{2}{*}{$\begin{array}{c}\text { Gas volume } \\
\text { Pressure difference } \\
\text { Model }\end{array}$} & \multicolumn{2}{|c|}{$60 m^{3} / h$} & \multicolumn{2}{|c|}{$70 m^{3} / h$} & \multicolumn{2}{|c|}{$80 m^{3} / h$} \\
\hline & $\begin{array}{l}\text { Simulated } \\
\text { result/kPa }\end{array}$ & $\begin{array}{c}\text { Absolute } \\
\text { value }\end{array}$ & $\begin{array}{l}\text { Simulated } \\
\text { result/kPa }\end{array}$ & $\begin{array}{c}\text { Absolute } \\
\text { value }\end{array}$ & $\begin{array}{l}\text { Simulated } \\
\text { result/kPa }\end{array}$ & $\begin{array}{c}\text { Absolute } \\
\text { value }\end{array}$ \\
\hline RNG k-e & 96.3 & 22.0383 & 124.4 & 22.1227 & 10.59 & 0.7798 \\
\hline $\mathrm{k}$-e with rotary flow & 106.5 & 24.4785 & 156.03 & 28.0019 & 167.7 & 27.1849 \\
\hline RSM & 4.74 & 0.1340 & 5.81 & 0.0799 & 6.13 & 0.0303 \\
\hline
\end{tabular}

\subsubsection{Verification of turbulence models}

To further verify the precision of turbulence models, 14 combinations of the orthogonal design (i.e., 3, 4, 7, 11, 12, 15, $16,20,23,24,27,28,31$, and 32) were selected. The verification results are recorded in Table 10. Error analysis shows that the mean error of simulated results was $8.21 \%$, that is, $91.79 \%$ of simulated results agree with test results.

Table 10. Comparison between the simulated results of 14 combinations of the orthogonal design and test results

\begin{tabular}{|c|c|c|c|c|}
\hline $\begin{array}{l}\text { Serial number of } \\
\text { combinations }\end{array}$ & Tool & $\begin{array}{c}\text { Simulated pressure difference } \\
\qquad \mathrm{p} / \mathrm{kPa}\end{array}$ & $\begin{array}{l}\text { Measured pressure difference } \\
\qquad \mathrm{Ap} / \mathrm{kPa}\end{array}$ & $\begin{array}{c}\text { Absolute } \\
\text { error }\end{array}$ \\
\hline 3 & $3-19020-3440-55-8$ & 7.62 & 8.61 & $11.50 \%$ \\
\hline 4 & $3-19025-38 \quad 45-60-10$ & 6.4 & 6.64 & $3.61 \%$ \\
\hline 7 & $3-20920-34 \quad 45-60-4$ & 6.35 & 6.23 & $1.93 \%$ \\
\hline 11 & $3-228 \quad 20-38 \quad 30-50-8$ & 4.75 & 4.78 & $0.63 \%$ \\
\hline 12 & $3-22825-34 \quad 35-45-10$ & 2.17 & 2.64 & $17.80 \%$ \\
\hline 15 & $3-24720-38 \quad 35-45-4$ & 6.61 & 6.57 & $0.61 \%$ \\
\hline 16 & $3-24725-3430-50-6$ & 3.94 & 4.29 & $8.16 \%$ \\
\hline 20 & $4-19025-2645-45-8$ & 5.54 & 5.37 & $3.17 \%$ \\
\hline 23 & $4-20920-3045-45-6$ & 9.64 & 8.2 & $17.56 \%$ \\
\hline 24 & $4-20925-2640-50-4$ & 4.24 & 4.64 & $8.62 \%$ \\
\hline 27 & $4-22820-26 \quad 30-55-10$ & 2.83 & 2.17 & $30.41 \%$ \\
\hline 28 & $4-228 \quad 25-3035-60-8$ & 4.44 & 4.49 & $1.11 \%$ \\
\hline 31 & $4-24720-2635-60-6$ & 5.49 & 5.51 & $0.36 \%$ \\
\hline 32 & $4-24725-30 \quad 30-55-4$ & 2.89 & 3.19 & $9.40 \%$ \\
\hline \multicolumn{4}{|c|}{ Mean } & $8.21 \%$ \\
\hline
\end{tabular}

\section{CONCLUSIONS}

(1) The critical liquid-carrying gas flow under test conditions was derived as $70 \mathrm{~m}^{3} / \mathrm{h}$ from the indoor test phenomena and the relevant calculation formula. Hence, the RFJT structural parameters were optimized through an orthogonal test with three gas volumes: $60 \mathrm{~m}^{3} / \mathrm{h}, 70 \mathrm{~m}^{3} / \mathrm{h}$, and $80 \mathrm{~m}^{3} / \mathrm{h}$, using different evaluation indices. Comprehensive data analysis shows that, to balance discharge volume with rotary flow height, the optimal structural parameters of the RFJT are as follows: number of side holes of throat pipe $=3$, throat pipe length $=247 \mathrm{~mm}$, nozzle diameter $=25 \mathrm{~mm}$, throat- nozzle distance $=38 \mathrm{~mm}$, pitch diameter $=45 \mathrm{~mm}$, helix angle $=50^{\circ}-60^{\circ}$, and wing width $=4-6 \mathrm{~mm}$. Under the gas volume of 60,70 , and $80 \mathrm{~m}^{3} / \mathrm{h}$, the optimized RFJT achieved a discharge volume of $1.69 \mathrm{~kg}, 1.79 \mathrm{~kg}$, and $3.46 \mathrm{~kg}$, respectively, which is better than that achieved by any tool in the orthogonal design.

(2) The influence of single parameter variation on gas-liquid flow state was analyzed. The results indicate that a spiral body with 2.25 rings and a draft pipe of $25 \mathrm{~mm}$ in diameter can effectively realize gas-liquid separation, and create rotary flow, facilitating the effective delivery of liquid.

(3) Taking the pressure difference between the inlet and outlet of the tool as the metric, the simulated results were 
compared with indoor test results to screen and verify the turbulence model. The results show that, the Euler-Euler model is suitable for multiphase flow, and Reynolds stress model is suitable for turbulence. The mean error of simulation was merely $8.21 \%$, i.e., $91.97 \%$ of simulated results agree with test results.

\section{ACKNOWLEDGEMENT}

This paper was supported by National Major Special Project "Research on artificial lift technology and matching technology of whole production process in $\mathrm{CO}_{2}$-drive Reservoirs" (Grant No.: 2016ZX05056004-002) and National Natural Science Foundation: "Identification and optimization of complex system based on Hybrid data and its application in low permeability oil wells" (Grant No.: 61572084).

\section{REFERENCES}

[1] Alamu, M.B. (2012). Gas-well liquid loading probed with advanced instrumentation. SPE Journal, 17(1): 251270. https://doi.org/10.2118/153724-PA

[2] Vortex Flow LLC. (2003). Gas Liquid Separator. The American Oil \& Gas.

[3] Lea, J.F., Nickens, H.V., Wells, M.R. (2008). Gas Well Deliquification: Solution to Gas Well Liquid Loading Problems, 1st Editions. Burlington, MA: Gulf Publishing.

[4] Putra, S.A., Christiansen, R.L. (2001). Design of tubing collar inserts for producing gas wells below their critical velocity. SPE Annual Technical Conference and Exhibition, New Orleans, Louisiana. https://doi.org/10.2118/71554-MS

[5] Lane, D.L., Prince, W.D., Miler, A. (2004). Flow development chamber for creating a vortex flow and a laminar flow. U.S. Patent 6,749,374 B1.

[6] Simpson, D.A. (2003). Vortex flow technology finding new applications. The Rocky Mountain Oil Journal, 83(45): 40-45.
[7] Krishna, M. (2009). Investigation of swirl flows applied to the oil and gas industry. Texas: A\&M University.

[8] Davailles, A., Climent, E., Bourgeois, F. (2012). Fundamental understanding of swirling flow pattern in hydrocyclones. Separation and Purification Technology, 92: 152-160. https://doi.org/10.1016/j.seppur.2011.12.011

[9] Wang, C., Dong, B., Sun, Y., Du, Q., Chu, H., Yi, J. (2015). Numerical simulation research of the influencing factor of vortex tool drainage gas recovery technology. The Open Petroleum Engineering Journal, 8(1): 64-71. https://doi.org/10.2174/1874834101508010064

[10] Rocha, A.D., Bannwart, A.C., Ganzarolli, M.M. (2015). Numerical and experimental study of an axially induced swirling pipe flow. International Journal of Heat and Fluid Flow, 53: 81-90. https://doi.org/10.1016/j.ijheatfluidflow.2015.02.003

[11] Lu, H.Q. (1989). The Theory and Application of Jet Pump Technology. Beijing: Water Resources and Hydropower Press.

[12] Chen, D.C., Yao, Y., Han, H., Fu, G., Song, T.J., Xie, S.X. (2016). Optiminization experiment on the liquid discharge effects and its structural parameters for gaswells vortex tool. Daqing Petroleum Geology and Development, 35(4): 109-112. https://doi.org/10.3969/J.ISSN.1000-3754.2016.04.021

[13] Chen, D.C., Fu, G., Yao, Y., Han, H., Song, T.J., Xie, S.X. (2016). Optimization of structural parameters for fluid-carrying in gas wells. Petroleum Drilling and Production Technology, 38(3): 400-404. https://doi.org/10.13639/j.odp.2016.03.024

[14] Liu, Y., Xie, C., Li, X., Lu, G., Tang, L., Tan, X. (2020). Optimization analysis of structure parameters of downhole vortex tool based on CFD and orthogonal studies. Journal of Petroleum Science and Engineering, 190:

107030 . https://doi.org/10.1016/j.petrol.2020.107030

[15] Guo, Y.N. (2015). Development of the Structural Parameters of Jetting Device and VFJT Optimized in Sulige Gas Field. Xi'an Shiyou University. 